\title{
IMPLEMENTASI METODE EVEN-RODEH CODE UNTUK KOMPRESI KITAB UNDANG-UNDANG HUKUM PIDANA (KUHP) BERBASIS ANDROID
}

\author{
Nopiyah Belia Batubara ${ }^{1}$, Taronisokhi Zebua ${ }^{2}$ \\ ${ }^{1}$ Program Studi Teknik Informatika STMIK Budi Darma, Medan, Indonesia \\ ${ }^{2}$ Program Studi Teknik Informatika AMIK Stiekom Sumatera Utara, Rantau Parapat, Indonesia \\ Email: ${ }^{1}$ nopiyahbeliabatubara@gmail.com, ${ }^{2}$ taronizeb@gamil.com
}

\begin{abstract}
Abstrak
Smartphone selain menjadi alat komunikasi smartphone, juga berfungsi sebagai alat untuk mencari informasi. Salah satu aplikasi yang saat ini banyak digunakan oleh siswa maupun masyarakat umum adalah aplikasi KUHP berbasis mobile. Aplikasi KUHP merupakan aplikasi yang berisikan hukum-hukum pidana. Aplikasi KUHP memiliki teks yang berukuran besar dan tersimpan dalam database aplikasi setelah terinstal. Besarnya ukuran database materi aplikasi KUHP menyebabkan dibutuhkannya ruang memori yang besar. Hal ini menjadi salah satu penyebab kinerja memori smartphone menjadi berkurang dan lambat. Teknik kompresi dapat digunakan sebagai salah satu solusi penyelesaian masalah di atas. Kompresi bertujuan untuk memampatkan ukuran data yang besar menjadi lebih kecil, sehingga ruang penyimpanan yang dibutuhkan menurun. Penelitian ini menguraikan bagaimana melakukan proses kompresi materi aplikasi KUHP berdasarkan algoritma Even Rodeh Code. Berdasarkan hasil pengujian yang dilakukan untu mengkompresi 280 bit data, diperoleh bahwa ukuran data setelah terkompresi adalah 176 bit dengan compression ratio sebesar $62,8 \%$, ratio of compression sebesar 1,59 bit, dan redudancy sebesar $37,2 \%$.
\end{abstract}

Kata kunci: Kompresi, Aplikasi, KUHP, Even Rodeh Code, Database

\begin{abstract}
Smartphones in addition to being a smartphone communication tool also functions as a tool for finding information. One application that is currently widely used by students and the public is KUHP application that run in mobile. KUHP application is an application that contains material of criminal laws. The KUHP application has large material and is stored in the application database after it is installed. The large size of the database of the Criminal Code application causes the need for large memory space at mobile. This has become one of the causes of smartphone memory performance to be reduced and slow. Compression technique can be used as a solution to the problem above. Compression aims to compress large data sizes into smaller ones, so that the required storage space decreases. This study describes how to do the compression process of the KUHP application material based on the Even Rodeh Code algorithm. Based on the results of tests conducted to compress 280 bits of data, it was found that the size of the data after being compressed was 176 bits, with compression ratio is 62.8\%, ratio of compression is 1.59 bits, and redundancy is $37.2 \%$.
\end{abstract}

Keywords: Compression, KUHP Aplication, Even Rodeh Code, Database

\section{PENDAHULUAN}

Perkembangan teknologi memungkinkan kita sebagai pengguna untuk menyimpan data di suatu media penyimpanan. Saat ini penyimpanan memiliki kapasitas yang cukup besar, namun tetap ada batasan tertentu bagi penyimpanan dalam banyaknya data yang dapat disimpan. Semakin besar kapasitas data yang akan disimpan, maka semakin besar pula ukuran kapasitas yang akan dibutuhkan pada media penyimpanan[1].

Aplikasi KUHP yaitu aplikasi yang berisikan informasi tentang undang-undang negara yang mengatur hukum pidana yang berasal dari buku KUHP. Pada aplikasi KUHP terdapat banyak teks undang-undang dalam KUHP, teks tersebut disimpan dalam database. Banyaknya teks yang tersimpan dalam database membuat database menjadi cepat penuh dan juga penyimpanan pada smartphone. Dengan hal tersebut maka, perlu dilakukan suatu teknik kompresi atau teknik pemampatan ukuran data. Kompresi adalah sebuah proses unuk meminimalkan kapasitas data asli dari suatu data atau informasi. Dengan memanfaatkan kompresi maka, kapasitas suatu data dapat diminimalisir sehingga ruang penyimpanan tidak menjadi cepat penuh dan mempercepat dalam proses transfer data[2].

Algoritma Even Rodeh Code merupakan algoritma kompresi data yang mengkodekan setiap karakter dengan menggunakan beberapa rangkaian bit. Pembentukan bit yang mewakili masing-masing karakter dibuat berdasarkan frekuensi kemunculan tiap karakter. Berdasarkan penelitian sebelumnya disimpulkan bahwa algoritma Even Rodeh Code lebih unggul dari pada Goldbach GO Code berdasarkan perbandingan rasio kompresi dan ruang penyimpanan[3].

\section{TEORITIS}

\subsection{Kompresi}

Kompresi data adalah proses mengubah masukkan data asli menjadi keluaran data yang memiliki kapasitas atau ukuran lebih kecil. Ada dua cara atau teknik yang dihasilkan dalam proses kompresi yaitu algoritma untuk eginput pesan atau teks dan menghasilkan sebuah representasi kompresi (dengan meminimalkan ukuran bit) atau Bahasa ilmu computer disebut algoritma encoding dan yang mengembalikan pesan asli atau teks asli dari representasi kompresi disebut algoritma decoding[4]. Beberapa faktor yang biasa digunakan untuk menganalisa kualitas suatu teknik kompresi data adalah [5] : 
1. Ratio of Compression $\left(R_{C}\right)$

Ratio of Compression $\left(R_{C}\right)$, yaitu nilai perbandingan antara ukuran bit data sebelum dikompresi dengan ukuran bit data yang telah dikompresi.

$R_{C}=\frac{\text { Ukuran bit data sebelum dikompresi }}{\text { Ukuran bit data setelah dikompresi }} \times 100 \%$

2. Compression Ratio $\left(C_{R}\right)$

Compression Ratio $\left(C_{R}\right)$, yaitu persentase perbandingan antara data yang telah dikompresi dengan data yang belum dikompresi.

$C_{R}=\frac{\text { Ukuran bit data setelah dikompresi }}{\text { Ukuran bit data sebelum dikompresi }} \times 100$

3. Redudancy $(\mathrm{Rd})$

Redudancy (Rd) merupakan persentasi dari hasil selisih antara ukuran data sebelum dikompresi dengan data setelah dikompresi .

$R d=100 \%-C_{R}$

\subsection{Kitab Undang-undang Hukum Pidana (KUHP)}

Hukum pidana memiliki dua pengertian berdasarkan prinsipnya yaitu hukum pidana objektif (Ius poenale) dan hukum pidana subjektif (ius puniendi). hukum pidana subjektif memiliki dua pengertian, yaitu [6] :

1. Pengertian dalam arti luas, hubungan antara hak negara atau alat-alat beserta perlegkapannya untuk memberikan atau meneutukan ancaman berupa pidana dari suatu perbuatan.

2. Pengertian dalam arti sempit, yaitu hak yang diberikan negara untuk menutut perkara-perkara pidana yang dijatuhkan dan dilaksanakan pidana kepada orang yang melakukan tindakan pidana.

\subsection{Algoritma Even Rodeh Code}

Algoritma Even Rodeh Code adalah algoritma kompresi data yang mengkodekan karakter-karakter dengan beberapa rangkaian bit yang mewakili karakter yang dibuat berdasarkan frekuensi setiap karakter. Kode yang dihasilkan sangat mirip dengan kode omega, perbedaan utama adalah bahwa panjang prepended sampai panjang 3 bit dicapai dan menjadi kelompok yang paling kiri dari kode.

Tahap membangun kode Even-Rodeh Code dengan n sebagai indeks dari karakter [3], yaitu:

1. Menghitung panjang bit.

2. Jika panjang bit $0<=\mathrm{n}<=3$ maka nilai $\mathrm{n}$ diubah ke biner, tambahkan 0 di depan nilai biner sehingga bit menjadi 3 digit.

3. Jika panjang bit $4<=\mathrm{n}<=7$ maka nilai $\mathrm{n}$ diubah ke biner, tambahkan $0 \mathrm{~d}$ ibelakang nilai biner sehingga bit menjadi 4 digit.

4. Jika panjang bit $n>=8$ maka nilai $n$ diubah ke biner,tambahkan 0 dibelakang nilai biner kemudian angka ditambahkan didepan nilai biner sebanyak jumlah digit nilai dalam biner.

Beberapa daftar kode Even-Rodeh Code dan jumlah bit kode Even-Rodeh Code berdasarkan frekuensi karakter dapat dilihat pada Tabel 1

Tabel 1. Even Rodeh Codes

\begin{tabular}{cc}
\hline $\boldsymbol{N}$ & Even Rodeh \\
\hline 0 & 000 \\
1 & 001 \\
2 & 010 \\
3 & 011 \\
4 & 1000 \\
7 & 1110 \\
8 & 10010000 \\
\hline
\end{tabular}

Langkah-langkah kompresi pada algoritma Even Rodeh Code [3], sebagai berikut :

1. Input teks dan lakukan penyimpanan.

2. Melakukan pembacaan teks.

3. Melakukan pengurutan dari karakter yang memiliki frekuensi terbesar ke frekuensi yang terkecil.

4. Membentuk tabel kode Even Rodeh Code. Melakukan pengkodean pada file yang akan di kompresi dengan tabel kode Even Rodeh Code. Setelah diganti hitung jumlah bit pada tiap nilai.

5. Melakukan penggabungan hasil string bit kode Even Rodeh Code. Terlebih dahulu di lakuakan pemeriksaan terhadap panjang string bit. 
Langkah-langkah dekompresi dengan menggunakan algoritma Even Rodeh Code [3] adalah:

1. Memasukkan hasil teks kompresi.

2. Hasil string bit kode Even Rodeh Code yang menjadi nilai file di rubah kembali ke bentuk biner.

3. Mengembalikan biner menjadi string bit semula dengan melakukan pembacaan pada 8 bit terakhir, hasil pembacaan berupa bilangan desimal. nyatakan hasil pembacaan dengan $\mathrm{n}$ lalu hilangkan bit pada bagian akhir sebanyak $7+\mathrm{n}$.

\section{ANALISA DAN PEMBAHASAN}

Penggunaan database pada sebuah aplikasi memang sangat mendukung fungsionalitas dari aplikasi, namun disisi lain, pemanfaatan database berukuran besar akan berakibat pada kebutuhan ruang penyimpanan yang besar. Aplikasi KUHP merupakan salah satu aplikasi yang memiliki ukuran database yang besar karena materi yang tersimpan di dalam database sangat banyak. Aplikasi KUHP berbasis mobile saat ini suda sangat banyak dimanfaatkan oleh siswa, maupun masyarakat umum, namun aplikasi ini tidak bekerja optimal karena keterbatasan kapasitas memori penyimpanan file yang dimiliki oleh smartphone yang digunakan masih terbatas. Pemanfaatan teknik pemampatan data dapat diterapkan pada kasus ini agar ukuran database aplikasi yang disimpan di dalam memori smartphone lebih kecil, sehingga kebutuhan ruang memori penyimpanan lebih kecil.

Algoritma Even Rodeh Code melakukan proses kompresi terhadap file materi KUHP pada saat aplikasi diinstal pada smartphone. Saat proses intalasi aplikasi dilakukan, maka dibuat satu file database aplikasi di dalam memori smartphone yang digunakan untuk menyimpan hasil komperesi materi KUHP. Dapat didefenisikan bahwa yang tersimpan ke dalam database aplikasi adalah file materi yang telah dimampatkan sehingga ukuran database menjadi jauh lebih kecil. Skema proses kompresi dan dekompresi diperlihatkan pada diagram berikut ini.

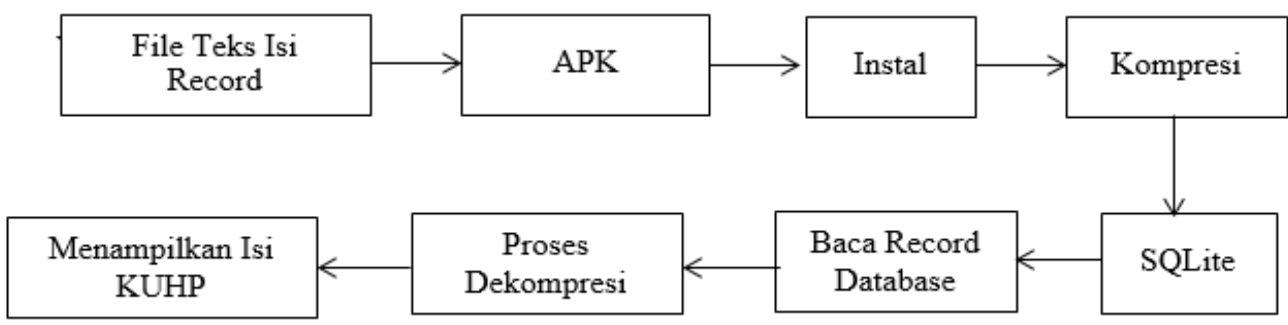

Gambar 1. Skema Proses Kompresi dan Dekompresi File Materi pada Aplikasi KUHP

Proses dekompresi dilakukan otomatis oleh aplikasi pada saat pengguna aplikasi memanggil record database materi yang ingin diakses, sehingga yang ditampilkan kepada pengguna adalah teks asli dari materi.

\subsection{Proses Kompresi Berdasarkan Algoritma Even Rodeh Code}

Berdasarkan analisa bahwa proses kompresi dilakukan pada saat proses instalasi aplikasi berlangsung. File materi yang telah disediakan akan dikompresi kemudian hasilnya akan disimpan menjadi record database aplikasi KUHP. Diasumsikan isi atau teks file materi yang dikompres adalah "penggunaan secara komersial ciptaan", maka proses yang dilakukan diuraikan berikut ini.

Karakter $=\sum=\{\mathrm{p}, \mathrm{e}, \mathrm{n}, \mathrm{g}, \mathrm{u}, \mathrm{a}, \mathrm{SP}, \mathrm{s}, \mathrm{c}, \mathrm{r}, \mathrm{k}, \mathrm{o}, \mathrm{m}, \mathrm{i}, \mathrm{l}, \mathrm{t}\}$

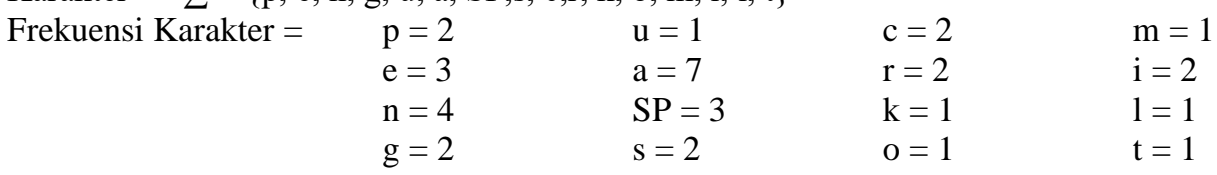

Setelah karakter dan frekuensi kemunculan tiap karakter diketahui, maka karakter akan diurutkan berdasarkan frekuensi kemunculannya mulai dari karakter dengan frekuensi kemunculan terbesar ke karakter dengan frekuensi kemunculan terkecil. Jika terdapat lebih dari satu karakter dengan frekuensi kemunculan yang sama maka diurutkan berdasarkan abjad. Untuk hasil pengurutan karakter dan frekuensi karakter dapat dilihat pada tabel 2.

Tabel 2. String Sebelum Dikompresi

\begin{tabular}{cccccc}
\hline Karakter & Frekuensi & $\begin{array}{c}\text { ASCII } \\
\text { Desimal }\end{array}$ & $\begin{array}{c}\text { ASCII } \\
\text { Binari }\end{array}$ & Bit & Frek x Bit \\
\hline $\mathrm{p}$ & 2 & 112 & 01110000 & 8 & 16 \\
$\mathrm{e}$ & 3 & 101 & 01100101 & 8 & 24 \\
$\mathrm{n}$ & 4 & 110 & 01101110 & 8 & 32 \\
$\mathrm{~g}$ & 2 & 103 & 01100111 & 8 & 16 \\
$\mathrm{u}$ & 1 & 117 & 01110101 & 8 & 8 \\
\hline
\end{tabular}




\begin{tabular}{cccccc}
\hline a & 7 & 97 & 01100001 & 8 & 56 \\
space & 3 & 32 & 00100000 & 8 & 24 \\
s & 2 & 115 & 01110011 & 8 & 16 \\
$\mathrm{c}$ & 2 & 99 & 01100011 & 8 & 16 \\
$\mathrm{r}$ & 2 & 114 & 01110010 & 8 & 16 \\
$\mathrm{k}$ & 1 & 107 & 01101011 & 8 & 8 \\
$\mathrm{o}$ & 1 & 111 & 01101111 & 8 & 8 \\
$\mathrm{~m}$ & 1 & 109 & 01101101 & 8 & 8 \\
$\mathrm{i}$ & 2 & 105 & 01101001 & 8 & 16 \\
$\mathrm{l}$ & 1 & 01101100 & 8 & 8 \\
$\mathrm{t}$ & 1 & 116 & 01110100 & 8 & 8 \\
\hline
\end{tabular}

Langkah selanjutnya adalah melakukan pengkodean dengan menggunakan Even Rodeh Code. Sebelum melakukan proses kompresi pada materi aplikasi KUHP, maka karakter materi akan dikodekan terlebih dahulu dengan kode Even Rodeh Code. Selanjutnya dilakukan proses kompresi dengan mengganti binary awal dengan kode Even Rodeh Code.

Tabel 3. Total Bit Pergantian Karakter Sesudah Dikompresi

\begin{tabular}{cccccc}
\hline $\mathbf{N}$ & Karakter & $\begin{array}{c}\text { Frekuensi } \\
\text { Karakter }\end{array}$ & $\begin{array}{c}\text { Kode Even Rodeh } \\
\text { Code }\end{array}$ & Bit & Frek x Bit \\
\hline 0 & $\mathrm{a}$ & 7 & 000 & 3 & 21 \\
1 & $\mathrm{n}$ & 4 & 001 & 3 & 12 \\
2 & $\mathrm{e}$ & 3 & 010 & 3 & 9 \\
3 & $\mathrm{sp}$ & 3 & 011 & 3 & 9 \\
4 & $\mathrm{p}$ & 2 & 1000 & 4 & 8 \\
5 & $\mathrm{~g}$ & 2 & 1010 & 4 & 8 \\
6 & $\mathrm{~s}$ & 2 & 1100 & 4 & 8 \\
7 & $\mathrm{c}$ & 2 & 1110 & 4 & 8 \\
8 & $\mathrm{r}$ & 2 & 10010000 & 8 & 16 \\
9 & $\mathrm{i}$ & 2 & 10010010 & 8 & 8 \\
10 & $\mathrm{u}$ & 1 & 10010100 & 8 & 8 \\
11 & $\mathrm{k}$ & 1 & 10010110 & 8 & 8 \\
12 & $\mathrm{o}$ & 1 & 10011000 & 8 & 8 \\
13 & $\mathrm{~m}$ & 1 & 10011010 & 8 & 8 \\
14 & 1 & 1 & 10011100 & 8 & $\mathbf{1 6 3}$ bit \\
15 & $\mathrm{t}$ & 1 & 10011110 & 8 & \\
\hline
\end{tabular}

Berdasarkan kode-kode even rodeh code string materi asli (tabel 3), maka dilakukan penyusunan kode-kode tersebut sesuai dengan posisi karakter string asli.

\begin{tabular}{|c|c|c|c|c|c|c|c|c|c|}
\hline$\underline{1000}$ & $\underline{010}$ & $\underline{001}$ & $\underline{1010}$ & $\underline{1010}$ & $\frac{1001001}{0}$ & $\underline{001}$ & $\underline{000}$ & $\underline{000}$ & $\underline{001}$ \\
\hline $\mathrm{P}$ & $\mathrm{e}$ & $\mathrm{n}$ & $\mathrm{g}$ & g & $\mathrm{u}$ & $\mathrm{n}$ & $\mathrm{a}$ & $\mathrm{a}$ & $\mathrm{n}$ \\
\hline$\underline{011}$ & $\frac{1001010}{\underline{0}}$ & $\underline{010}$ & $\underline{1100}$ & $\underline{000}$ & $\underline{1110}$ & $\underline{000}$ & $\underline{011}$ & $\frac{1001011}{\underline{0}}$ & $\frac{100110}{\underline{00}}$ \\
\hline spasi & $\mathrm{S}$ & $\mathrm{e}$ & $\mathrm{c}$ & $\mathrm{a}$ & $\mathrm{r}$ & $\mathrm{a}$ & $\begin{array}{c}\text { spas } \\
\mathrm{i}\end{array}$ & $\mathrm{k}$ & o \\
\hline$\underline{100110}$ & $\underline{010}$ & $\underline{111}$ & $\underline{1001010}$ & $\underline{1001000}$ & $\underline{000}$ & $\underline{1001110}$ & $\underline{011}$ & $\underline{1100}$ & $\underline{100100}$ \\
\hline$\underline{10}$ & & $\underline{0}$ & $\underline{0}$ & $\underline{0}$ & & $\underline{0}$ & & & $\underline{10}$ \\
\hline M & $\mathrm{e}$ & $\mathrm{r}$ & $\mathrm{s}$ & $\mathrm{i}$ & $\mathrm{a}$ & 1 & spas & c & $\mathrm{i}$ \\
\hline
\end{tabular}




\begin{tabular}{|c|c|c|c|}
\hline 1000 & $\begin{array}{c}1001111 \\
0\end{array}$ & 000 & 000 \\
\hline$P$ & $\mathrm{t}$ & $\mathrm{a}$ & $\mathrm{a}$ \\
\hline
\end{tabular}

Sehingga setelah digabungkan, diperoleh string bit berikut :

10000100011010101010010010001000000001011100101000101100000111000001110010110100110001001101001 01110100101001001000000010011100011110010010000100010011110000000001

Langkah selanjutnya adalah melakukan penambahan bit (padding bit) dan flag bits dengan ketentuan bila sisa hasil bagi 8 dari panjang string bit yang dihasilkan di atas adalah 0, maka tambahkan 00000000 dibagian akhir string bit di atas (nyatakan dengan bit akhir). Sedangkan bila sisa hasil bagi 8 dari string bit di atas adalah $\mathrm{n}(1,2,3,4,5,6,7)$, maka tambahkan string 0 sebanyak $7-\mathrm{n}+$ "1" di akhir string bit (nyatakan dengan L). Lalu tambahkan bilangan biner dari $9-\mathrm{n}$ (nyatakan dengan bit akhir).

Berdasarkan jumla string bit yang dihasilkan dari gabungan keseluruhan kode Even Rodeh Code dari string materi di atas adalah 163 bit dan tidak habis dibagi 8 (sisanya 3 bit), maka perhitungannya sebagai berikut :

$\mathrm{n}=$ jumlah bit string hasil kompresi $/ 8_{-}=163 / 8=3$ (sisa).

kemudian cari bit padding dengan formula $7-\mathrm{n}+" 1 "=7-3+" 1 "=4+$ "1" buat bit 0 sebanyak 4 bit 00001 . Bit flagging dicari dengan cara $9-\mathrm{n}=9-3=6$, kemudian hasil bit flagging dirubah menjadi biner dengan representasi 8 bit. sehingga 6 dalam biner adalah 00000110. Sehingga string bit setelah penambahan padding dan flagging bit hasil akhir proses kompresi menjadi :

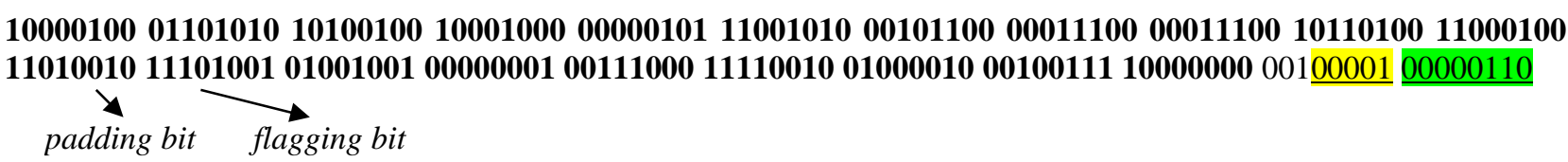

Total panjang bit keseluruhan setelah dilakukan penambahan bit padding dan flagging adalah $163+5+8=176$ bit . Biner hasil kompresi di atas akan dikonversi ke bentuk karakter dengan terlebih dahulu mengelompokkan bit tersebut menjadi 8 bit per kelompok, kemudian merubahnya menjadi karakter. Karakter yang dihasilkan inilah yang kemudian disimpan menjadi record database aplikasi KUHP. Berdasarkan karakter yang dihasilkan, maka jumlah karakter hasil kompresi adalah 22 karakter, yaitu "jla $\mid E$, AOér 8ób' $E$ !-

Jumlah karakter asli adalah 35 karakter, setelah dikompresi menghasilkan 22 karakter, jadi diketahui bahwa ada pengurangan sebanyak 13 karakter.

Berdasarkan hasil kompresi dengan Even Rodeh Code di atas, maka dilakukan proses perhitungan aspek Ratio of compression, Compression ratio dan Redudancy sebagai berikut :

Ukuran data sebelum dikompresi $=280$ bit $(35$ karakter $)$

Ukuran data setelah dikompresi $=176$ (22 karakter)

1. Ratio of compression $(\mathrm{Rc})$

$$
R_{C}=\frac{\text { Ukuran bit data sebelum dikompresi }}{\text { Ukuran bit data setelah dikompresi }}=\frac{280}{176}=1.59 \text { bit }
$$

2. Compression ratio

$$
C_{R}=\frac{\text { Ukuran bit data setelah dikompresi }}{\text { Ukuran bit data sebelum dikompresi }} \times 100 \%=\frac{176}{280} \times 100 \%=62,8 \%
$$

3. Redudancy $(\mathrm{Rd})$

$\mathrm{Rd}=100 \%-C_{R}=100 \%-62,8 \%=37,2 \%$

\subsection{Proses Dekompresi Berdasarkan Algoritma Even Rodeh Code}

Proses dekompresi dilakukan untuk menampilkan materi KUHP sesuai dengan judul materi yang ingin dibaca oleh pengguna aplikasi. Teks yang di-dekompresi adalah record database sesuai dengan judul materi yang dipilih. Record materi yang dipilih akan dirubah menjadi biner kemudian benir-biner tersebut akan didekompresi untuk menghasilkan teks asli dari materi yang dipilih. Dimisalkan judul materi yang dipilih oleh pengguna aplikasi adalah biner hasil kompresi pada contoh dalam penelitian ini.

Biner yang akan didekompresi adalah :

1000010001101010101001001000100000000101110010100010110000011100000111001011010011000100 1101001011101001010010010000000100111000111100100100001000100111100000000010000100000110

Proses dekompresi dilakukan dengan terlebih dahulu menentukan panjang string bit yang harus dibaca dengan menghitung padding dan flagging. Total panjang string bit (176 bit) terkompresi dikurangi total jumlah panjang 
padding dan flagging dari string di atas terdapat padding sebanyak 5 bit dan flagging sebanyak 8 bit, yang terdiri dari biner 6 (00000110), maka desimal $n=6$, hilangkan bit pada bagian akhir sebanyak $7+n, 7+6=13$, maka diperoleh panjang string bit yang harus dibaca adalah $176-13=163$ bit. String bit dari pengurangan padding dan flagging sebagai berikut :

10000100011010101010010010001000000001011100101000101100000111000001110010110100110001001101001 01110100101001001000000010011100011110010010000100010011110000000001

Setelah diperoleh string bit seperti semula, langkah selanjutnya lakukan pengecekan dari bit pertama, apabila terdapat pada tabel kode Even Rodeh Code sebelumnya, maka ubah string yang sesuai. Pembacaan string bit dilakukan dari indeks pertama sampai indeks terakhir dengan terus menambahkan biner pada indeks sebelumnya. Indeks ke $1=1$ tidak terdapat dalam tabel, indeks ke $2=10$ tidak terdapat dalam tabel, indeks ke $3=100$ juga tidak terdapat pada tabel, indeks ke $4=1000$ terdapat di dalam tabel bahwa 1000 karakter dari p, maka p dituliskan ke dalam database, begitu seterusnya sampai indeks terakhir. Sehingga dihasilkan string semula yaitu "penggunaan secara komersial ciptaan".

\section{HASIL DAN IMPLEMENTASI}

Penelitian ini diimplementasikan pada aplikasi KUHP yang berjalan pada mobile android. Sebelum proses instalasi dilakukan, maka disiapkan beberapa file materi KUHP. File materi ini akan dikompresi pada saat proses instalasi aplikasi berlangsung. Hasil kompresi dari file materi ini yang akan disimpan menjadi record database aplikasi dan disimpan di dalam media penyimpanan smartphone yang digunakan oleh pengguna, sehingga pada saat pengguna ingin melihat materi KUHP, maka terlebih dahulu dilakukan proses dekompresi materi yang dipilih tersebut untuk menampilkan isi materi yang sebenarnya.

1. File Materi dan File Setup KUHP

File materi asli dari aplikasi KUHP dibuat pada file dokumen word dan serta file instalasi aplikasi KUHP yang dibangun dengan bahasa pemrograman java.

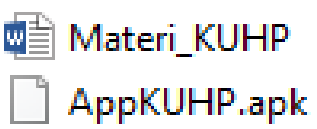

Gambar 2. File Materi dan Setup Instalasi Aplikasi KUHP

2. Tampilan Halaman Utama Aplikasi KUHP dan Halaman daftar Materi Aplikasi KUHP
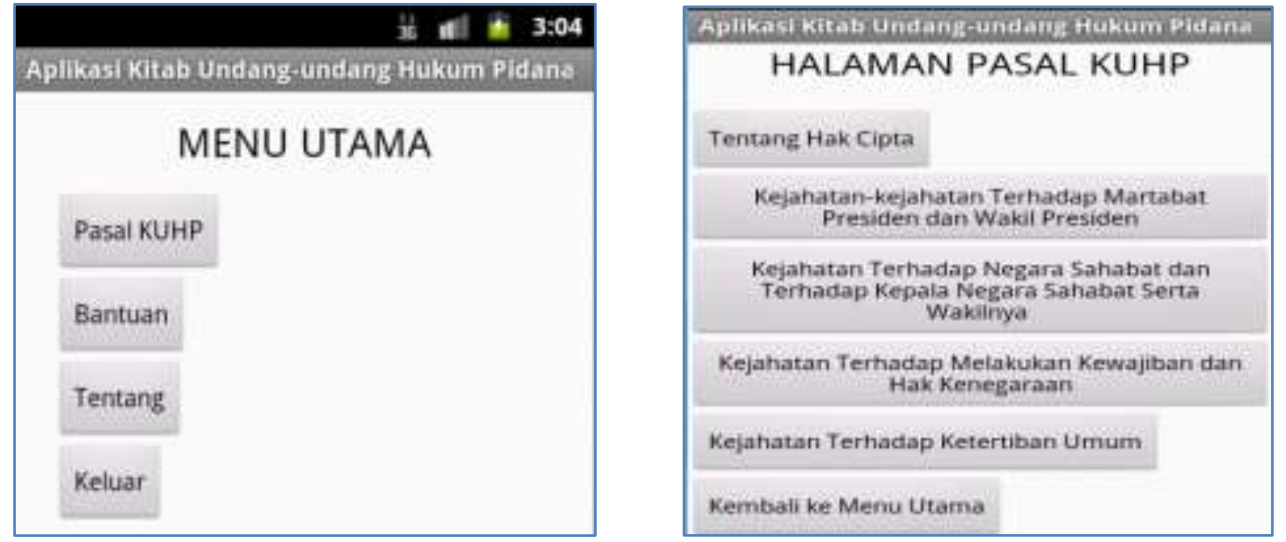

Gambar 3. Halaman Utama dan Daftar Materi Aplikasi KUHP

3. Tampilan halaman materi KUHP

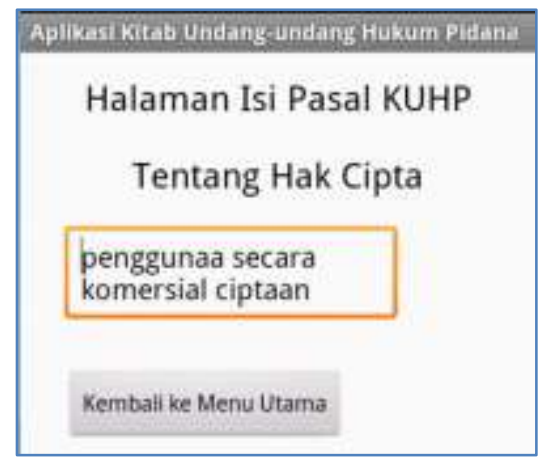

Gambar 4. Halaman Materi Aplikasi KUHP 
Berdasarkan analisa dan implementasi yang telah dilakukan, maka dilakukan pengujian terhadap tiga contoh teks materi untuk mengetahui performa kinerja kompresi berdasarkan aspke nilai Ratio Compression (RC), Compresi Ratio (CR) dan Redundancy (Rd). Hasil pengujian disajikan pada tabel 4.

Tabel 4. Hasil Pengujian Kompresi

\begin{tabular}{|c|c|c|c|c|c|c|}
\hline \multirow{2}{*}{ No } & \multirow{2}{*}{ Teks Asli } & \multicolumn{2}{|c|}{ Size File } & \multirow{2}{*}{ RC } & \multirow{2}{*}{ CR } & \multirow{2}{*}{ Rd } \\
\hline & & Sebelum & setelah & & & \\
\hline 1 & $\begin{array}{l}\text { penggunaan secara komersial } \\
\text { ciptaan }\end{array}$ & 280 bit & 176 bit & 1,59 bit & $62,8 \%$ & $37,2 \%$ \\
\hline 2 & $\begin{array}{l}\text { Pasal 131:Tiap-tiap penyerangan } \\
\text { terhadap diri Presiden atau Wakil } \\
\text { Presiden, yang tidak termasuk }\end{array}$ & 199 byte & 150 byte & 1,32 byte & $75 \%$ & $25 \%$ \\
\hline 3 & $\begin{array}{l}\text { penjara paling lama delapan tahun. } \\
\text { Pasal 139b: Makar dengan maksud } \\
\text { meniadakan atau mengubah secara } \\
\text { tidak sah .......................... } \\
\text { paling lama empat tahun. }\end{array}$ & 188 byte & 98 byte & 1,91 byte & $52,1 \%$ & $47,9 \%$ \\
\hline
\end{tabular}

Kesimpulan pada kompresi record database KUHP yaitu dari pengujian yang dilakukakan terhadap tiga isi KUHP kompresi berhasil dilakukan. Ukuran materi setelah terkompresi berkurang atau lebih sedikit dibanding ukuran sebelum dikompresi.

\section{KESIMPULAN}

Berdasarkan analisa yang telah diuraikan, maka kesimpulan dari penelitian ini adalah :

1. Proses kompresi record database pada aplikasi KUHP menggunakan algoritma Even Rodeh Code, dilakukan dengan mengkodekan tiap-tiap karakter berdasarkan kode yang telah ditentukan pada tabel kode Even Rodeh Code.

2. Algoritma Even Rodeh Code mengurutkan terlebih dahulu karakter yang memiliki frekuensi kemunculan terbesar ke terkecil, sehingga karakter yang dimanfaatkan lebih banyak. Berdasarkan pada parameter kompresinya algoritma ini cukup efisien dalam melakukan kompresi teks record database KUHP.

3. Aplikasi KUHP yang telah dilengkapi dengan fitur kompresi terhadap database materi aplikasi mampu bekerja dengan efektif khususnya kebutuhan ruang penyimpanan database yang jauh lebih kecil pada memori atau media penyimpanan di smartphone.

\section{REFERENCES}

[1] S. D. Nasution, "Perancangan Aplikasi Kompresi File Teks Dengan Menerapkan,” Jurnak Infotek STIEKOM, vol. 1, no.1, pp. 2008-2010, 2016.

[2] H. C. Rustamaji, Mariani and B. Yuwono, "APLIKASI KOMPRESI DATA MENGGUNAKAN METODE HUFFMAN STATIK PADA PERANGKAT MOBILE,” TEIEMATIKA, vol.11, no.1, pp. 9-18, 2014

[3] S. N. Kane, A. Mishra, and A. K. Dutta, "Preface: International Conference on Recent Trends in Physics (ICRTP 2016)," J. Phys. Conf. Ser., vol. 755, no. 1, 2016.

[4] G. M. S. David, Handkbook Of Data Compression, 5th ed. London, 2010.

[5] D. A. Yansyah, "Perbandingan Metode Punctured Elias Code dan Huffman pada Kompresi File Text," JURIKOM (Jurnal Ris. Komputer), vol. 2, no. 6, pp. 33-36, 2015.

[6] A. Sofyan, N. Azisa, Buku Ajar Hukum Pidana, Makasar, Pustaka Pena Press, 2016. 